\title{
BOOK REVIEW: Mohanty, A. K. (2019). The Multilingual Reality: Living with Languages. Bristol, United Kingdom: Multilingual Matters. 272 pages. ISBN: 978-1788921954
}

\author{
Anna M. Farrell ${ }^{1}$ \\ Concordia University, USA
}

Mohanty's (2019) The Multilingual Reality: Living with Languages is a thorough and alarming analysis of the systematic stigmatization of Indigenous, tribal, and minoritized (ITM) languages. This book has clear implications for the field of comparative and international education, particularly regarding mother-tongue based multilingual education (MTB-MLE) as a way to address access and quality debates.

The book begins with an overview of multilingualism, narrowing in on the multilingual context of India, in particular. This is followed by a discussion of a series of studies from the 1980s and 1990s that Mohanty conducted in Odisha state among the Kond people, some of whom are Kui-Odia bilingual and others who are Odia monolingual speakers. These studies are unique in that they do not consider English or another dominant language, but rather consider an Indian national language (Odia) and an ITM language (Kui). The findings from these two decades worth of studies reaffirm that multilingual individuals experience cognitive advantages over monolinguals.

Having set the stage with the background studies, Mohanty moves into the heart of his argument, that ITM languages are routinely displaced from domains such as schools and markets and are relegated to the home. Perhaps the most important conceptual contribution of this book is the idea of the "double divide" (p. 88) in which significant power gaps between different types of languages contribute to the global loss of linguistic diversity as well as discrimination in education. Mohanty lays out the double divide as a pyramid where at the top, in limited supply, are dominant global languages like English and French. Such languages enjoy high levels of prestige and provide speakers access to education, formal employment, and often higher socio-economic status. The first divide separates out a larger middle tier of national or vernacular languages such as Hindi, Odia, and the other 22 official languages of India, which are common languages of employment and education, but do not necessarily command the same prestige as the top-tier languages. The second divide separates national languages from the largest and least powerful group, the ITM languages.

\footnotetext{
${ }^{1}$ Correspondence: Anna Farrell, Concordia University, St. Paul, Doctorate in Education Program, 1282 Concordia Avenue, St. Paul, MN 55104; afarrell@csp.edu
} 


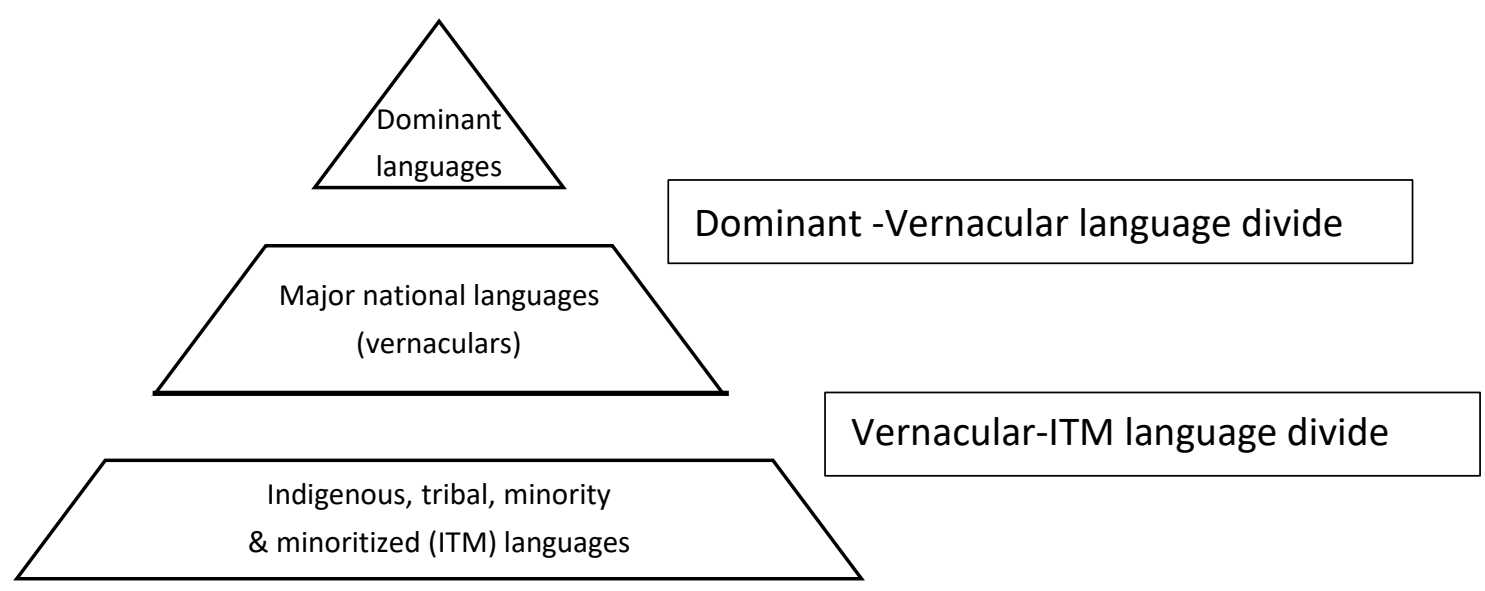

Figure 1. The double divide in multilingualism, modified from Mohanty (2019, p. 88)

The implications of the double divide are serious. Dominant languages are perceived to have instrumental benefits, whereas ITMs are seen to have value primarily as in-group identity markers. Mohanty demonstrates that the perceived instrumental benefits of Odia (national language) medium education have led parents to reject the idea of Kui (mother tongue) education for their children. By refusing Kui medium education, the instrumental benefits of the more dominant Odia are reified and Kui is further marginalized. In addition, students who are submerged in unfamiliar languages at school are highly likely to drop out or be pushed out of school, exacerbating a cycle of poverty, educational neglect, and language loss, hardly the outcomes parents envision when rejecting mother tongue education. Mohanty is careful to point out that these processes are not unique to Kui and Odia, but observable in other multilingual communities around India and the world.

Another troubling finding is that when some ITM language communities have taken "collective action for assertive maintenance" (p. 112), violence has erupted between the marginalized language community and both dominant and other marginalized communities. Mohanty notes instances of this phenomenon in Odisha and Assam in India as well as in Sri Lanka. While this is not necessarily a common occurrence, it is noteworthy that attempted language maintenance efforts can be perceived as threatening and used as justification to oppress ITM communities further.

The final chapters consider language education policy in India, models for MTB-MLE, and the role of English as a dominant global language and an official language of India. While numerous attempts at more inclusive language education policies in India have been made, much of what has been attempted has failed, most notably the three-language formula (Agnihotri, 2006; Groff, 2017; Jhingran, 2005; Mohanty, 2010; Sonntag, 2002). Under the initial three-language formula, all students in India were to have access to education in their mother tongue or a regional language, Hindi or another national language, and English or another European language (p. 149). This was not a success according to Mohanty, for several reasons: the differences between mother tongues and regional languages were ill defined; the mother tongue was intended primarily as a transitional language for tribal children, to be phased out in favor of a regional or national language by grade three (an issue exacerbated by the lack of clarity around the terms mother tongue and regional language); and the formula was frequently revised, with different languages being added or subtracted.

More recently, local and regional attempts have been made to implement MTB-MLE for ITM language communities, including an early-exit transitional program in Odisha using 
two ITM languages, Kui and Saora. Mohanty finds that students in this program and others across India have seen increased attendance and retention, achievement, and self-confidence (p. 173). Despite these successes and the fact that they have greater potential to improve teaching and learning, developing late exit programs and scaling up nationally have proven to be difficult. If there is a critique be made of this book, it is here. Mohanty interrogates the issues around the oppression of ITM languages in great depth and argues clearly for MTBMLE. However, he stops short of offering potential national-level solutions for broader implementation of MTB-MLE, suggesting instead that multilingual education in India may still be "a bridge too far" (p. 174). Mohanty rightly points out that political and bureaucratic concerns get in the way of efforts to scale up programs effectively, but it would still be helpful to learn his thoughts on this particularly thorny issue.

Political challenges aside, perhaps the largest issue complicating efforts at implementing MTB-MLE is role of English in Indian society. It might be argued that there is actually a triple divide, with English the as the very tip of the double divide pyramid. Indeed, the last chapter begins with an evocative narrative about a community consecrating an idol of the Goddess English. English medium education is frequently equated with being educated, even when people have completed schooling in another language. Mohanty is not alone in his findings regarding the value placed on English. Scholars such as Kaiper (2018) have found that being literate in English is equated with "real" literacy, even when students can read and write in their home languages. Mohanty remains hopeful nonetheless, concluding with this call for MTB-MLE that should be taken to heart by scholars and practitioners globally: "Multilingual societies need MLE not because it facilitates learning of other and 'dominant' languages, but because it is high-quality education which can be empowering” (p. 183).

\section{References}

Agnihotri, R. K. (2006). Identity and multilinguality: The case of India. In A. B. M. Tsui \& J. W. Tollefson (Eds.), Language policy, culture, and identity in Asian contexts (pp. 185-204). Mahwah, NJ: Lawrence Erlbaum Associates.

Groff, C. (2017). Language and language-in-education planning in multilingual India: A minoritized language perspective. Language Policy, 16(2), 135-164.

Jhingran, D. (2005). Language disadvantage: The learning challenge in primary education. New Delhi, India: Nangia APH.

Kaiper, A. (2018). "If you don't have English, you're just as good as a dead person": A Narrative of Adult English Language Literacy Within Post-Apartheid South Africa. International Review of Education, 1-21.

Mohanty, A. K. (2010). Languages, inequality and marginalization: Implications of the double divide in Indian multilingualism. International Journal of the Sociology of Language, 205, $131-154$.

Sonntag, S. K. (2002). Minority language politics in North India. In J. W. Tollefson (Ed.), Language policies in education: Critical issues. Mahwah, NJ: Lawrence Erlbaum Associates. 


\begin{abstract}
About the Author
Anna Farrell is a contract professor of practice in the Doctorate in Education program at Concordia University, St. Paul. She also coordinates the Waseda Program, a study abroad program for Japanese students, at Lawrence University of Wisconsin. Dr. Farrell's research interests include language education policy in non-formal educational contexts, linguistic landscapes, and citizenship and identity. Her dissertation focused on the relationship between Irish dance and the Irish language, and how non-formal educational institutions play a role in (re)creating language attitudes and ideologies.
\end{abstract}

